\title{
The Effect of Chronic Diseases on the Use of Health Technology and Digital Services in the Elderly Population in Finland
}

\author{
Jukka MIELONEN ${ }^{\mathrm{a}, 1}$, Ulla-Mari KINNUNEN ${ }^{\mathrm{b}}$, Kaija SARANTO ${ }^{\mathrm{b}}$, \\ Anssi KEMPPI ${ }^{\mathrm{c}}$ and Hanna KUUSISTO ${ }^{\mathrm{b}}$ \\ ${ }^{a, b}$ Department of Health and Social Management, University of Eastern Finland \\ ${ }^{c}$ Finnish Pensioners' Federation, Finland
}

\begin{abstract}
Digital services are growing in the health-care field. The population in Europe is aging, and digital services are on the rise. There are also plenty of new health-care devices on the market. The aim of this study was to survey how elderly people cope with digital services or devices, especially if they are chronically ill. This quantitative study focuses on the impact of chronic diseases on the use of health technology and digital services. The target group of this study is Finnish people aged 65 or over. Based on the results, a chronic disease or disability is not an obstacle to the use of digital services or health-care technology in the Finnish elderly population. The main obstacles to the use of health technology or digital services are complexity, obscure text, or small font size. According to this study, elderly people seem to trust the device or application. Devices, applications, and online services should be designed so that elderly people's diseases or ability to function are considered.
\end{abstract}

Keywords. Health care, Digital services, Health technology, Disease

\section{Introduction}

The cost of health care is threatening to rise in Europe due to the aging population. The cost-effectiveness of health care can be improved by implementing digital technology. Increasing the role of self-care enables health professionals to monitor the progress of symptoms of certain diseases. Home-based health-care devices should be designed for various age-groups and diseases. Even though care processes and interventions are intended to support the use of digital technologies at home, the level of health technologies to be used at home has remained low [1,2]. The potential effects of various diseases must be considered when designing digital social and health-care services and devices [3]. A certain disease may have a negative impact on the used health-care device. In this study, health-care devices and meters mean, for example, blood glucose meters or spirometry.

Digital services are least used by those who would benefit most from them, and this can lead to a digital divide. Sociodemographic factors, and especially age, have an influence on the use of digital health-care services in people with chronic diseases. Elderly people do not have devices, or they do not know how to use the technology or

\footnotetext{
${ }^{1}$ Jukka Mielonen, PhDs, University of Eastern Finland, Department of Health and Social Management, Yliopistonranta 1, 70210 Kuopio, Finland; E-mail: jukmi@student.uef.fi
} 
digital services. They might be afraid of losing personal contacts when using digital services. Income and education seem to influence the use of digital services. Higher income or higher education may increase usage [4,5].

Aging also affects vision, hearing, motor functions, and coordination. The text of an application may be too small, and difficulties in eye-hand coordination and motor disabilities may slow down keyboard or mouse usage [6,7]. Many diseases, such as arthritis, may cause fine motor control and coordination changes. Cognitive capabilities may decrease, and elderly people may perceive technology differently from younger adults. These constraints force designers to create better products for elderly people $[8,9]$. However, no relationship between self-management of internet-based health information technologies and technology acceptance of patients with heart disease has been found [10].

This article describes how various chronic diseases or disabilities affect the use of digital health-care services, devices, or applications among elderly people. The following research question was set:

How does a possible disease affect the use of digital health-care services or devices?

\section{Methods}

The target group of this quantitative study is Finnish people older than 64 years of age. There were approximately 1.2 million people, or about $22 \%$ of the population, aged 65 and higher in Finland at the end of 2018, according to Statistics Finland [11]. The questionnaire was formed by operationalizing the variables of UTAUT (Unified Theory of Technology Acceptance) theory [12]. There was a total of 39 questions, of which two were open questions. The questionnaire was carried out using an Eduix E-form. The responses consisted of 'yes - no' answers (for which some of the answers requested more information in the text field), multiple choice, and rankings on a 5-point Likert scale (very often, often, sometimes, rarely or I never and completely agree, partially agree, partially disagree, completely disagree or I cannot say). The form also provided readymade response options for diseases. Some of the questions were not addressed to the respondent if the preceding value on the form was not met. These values included a disease or a device used to treat illness [13].

Information on the study and a link to the questionnaire were sent to members of the Finnish Pension Association by e-mail. Finnish Pensioners' Federation advertised the research on its own website and on the SeniorSurf website. The research was also advertised on social media, websites, and various publishing sites (e.g. LinkedIn and Facebook). It was possible to respond to the survey with assistance if a respondent was unable to open the survey themselves. The data was collected during the three-month period of March to May 2019.

The research data was analyzed using IBM SPSS Statistics 25 and 26. Both sociodemographic and disease-related ratios were calculated from the data. During the analysis phase, Likert-scale responses were reclassified by combining categories such as very often and often as one answer. A chi square test was used to examine the statistical dependence of background variables on the variables to be studied, and Pearson's correlation coefficient was used to examine the links between the variables. Open responses were analyzed using inductive content analysis. In content analysis, open 
responses were simplified and grouped into parent categories using descriptive expressions. The statistics to be reported were calculated from the main categories.

\section{Results}

Of the respondents to the survey $(\mathrm{N}=978)$, almost half had some underlying disease. Most of the respondents had some form of heart disease $(22.2 \%)$. The diseases and their incidence in subjects are presented in Table 1. Almost half of the respondents $(44.9 \%)$ had high incomes ( $>€ 3000$ per month) and a high level of education (a college or university degree).

Table 1. Respondents' diseases $(n=978)$.

\begin{tabular}{lrr}
\hline Disease & n & $\mathbf{\%}$ \\
\hline Heart disease & 217 & 22,2 \\
Musculoskeletal disorders & 192 & 19,6 \\
\hline Diabetes & 125 & 12,8 \\
Rheumatic disease & 46 & 4,7 \\
Psychiatric disorder & 10 & 1 \\
Parkinson's disease & 9 & 0,9 \\
Memory illness & 6 & 0,6 \\
\hline
\end{tabular}

In addition to the pre-completed answers, the questionnaire included an open followup question: I have another disease, what? This question was answered by $52.2 \%$ of the respondents, and 18 of the responses were rejected due to incomplete answers. The replies were classified in the upper classes of the ICD-10 classification [14]. The results are shown in Figure 1.

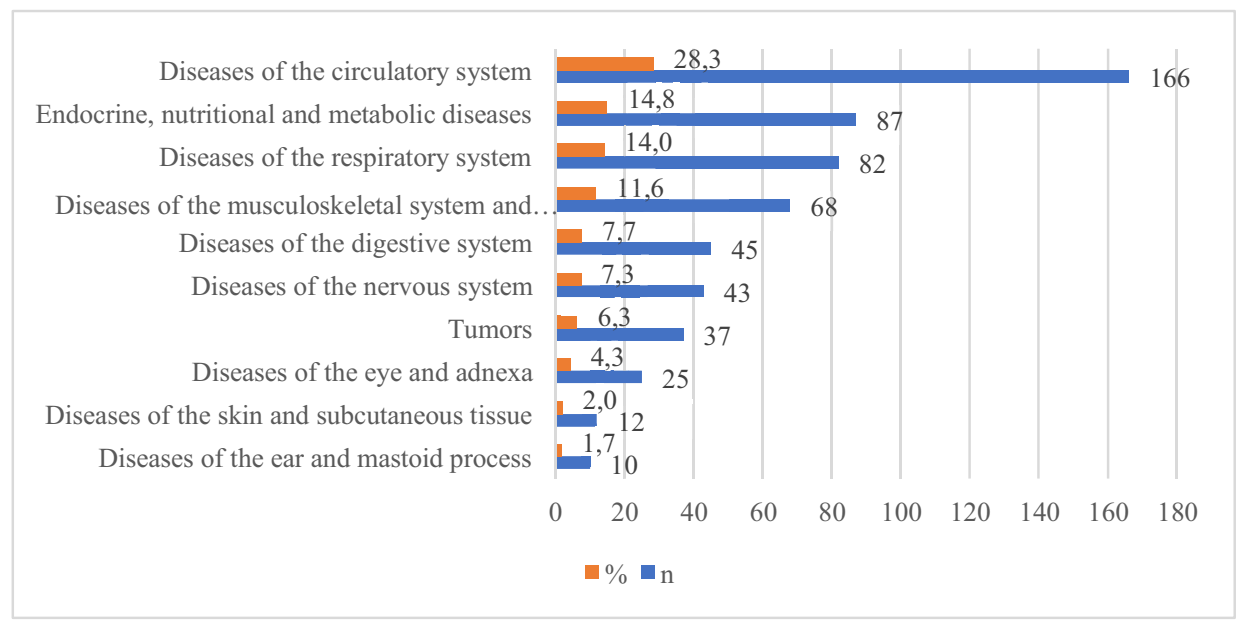

Figure 1. Responses classified according to the ICD-10 disease classification $(n=586)$. 
The respondents' functional ability or disease does not appear to prevent the use of digital services. Only a few of the respondents $(8.1 \%)$ reported that their functional ability or disease prevents the use of digital services. The chi square test showed the relation between morbidity and the use of digital services to be statistically very significant.

Only $13.0 \%$ of the respondents were using a device or an application for a disease or health monitoring. The majority $(68.1 \%)$ of the respondents who were using healthcare applications or devices were using a device or application (e.g. blood pressure or blood glucose meter) for diagnosing, controlling, treating, or alleviating a disease. Devices for the diagnosis, monitoring, treatment, alleviation, or compensation of an injury or defect (e.g. pacemaker) were used by $12.5 \%$ of the respondents, and $4.2 \%$ of the respondents were using the device for the study, replacement, or modification of an anatomical or physiological function (e.g. spirometers). The majority $(81.9 \%)$ trusted the device or application. The obstacles to the use of the IT device or application are shown in Figure 2.

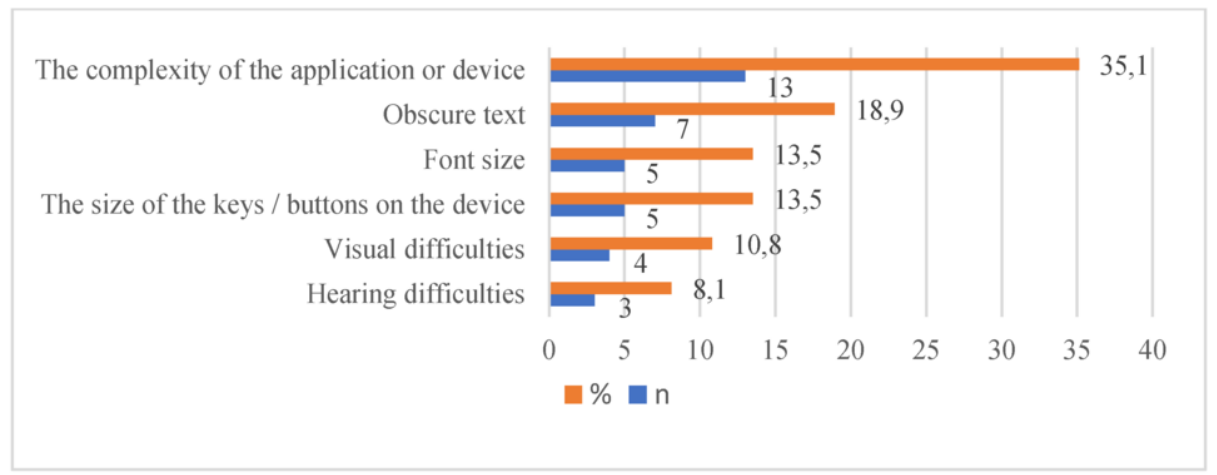

Figure 2. Barriers to use of the IT device or application.

\section{Reflection and Conclusions}

According to previous studies elderly people may not have necessary digital health devices or they are afraid to use them [4]. Furthermore, it has been shown that motor disabilities may slow down or cause errors in the use of a keyboard or mouse and eyehand coordination problems may affect the use of digital health-care services [6,7] However this study shows that in Finland elderly people have the necessary devices at home, and they can use them. Furthermore they trust the devices or applications, regardless of their disease or disability. As a person's chronic disease or disability does not appear to inhibit the use of digital health services or devices at home, a part of face to face visits among elderly could be replaced with telecare combined with remote monitoring increasing patient involvement.

According to this study, obstacles to the use of a health-care device or application include obscure text and the complexity of the application or device. However, there was a small proportion of respondents with these claims. The main obstacle for elderly people in the use of a health-care device or application is its complexity. Software developers and device engineers should focus more on elderly people's demands and should consider their possible disease or functional ability, as shown previously [8]. The devices should have bigger buttons or a larger font size. Since Finnish elderly people are willing and competent to use electronic health-care services and devices. We recommend that health- 
care providers increase the amount and variety of digital health solutions for elderly. A previous study shows that there is no relationship between technology acceptance and internet-based health information technologies [10]. The UTAUT model seeks to predict the use of technology based on intended use. Use behavior is influenced by performance expectancy, effort expectancy, social influence, and facilitation conditions [12]. Based on our research, elements such as effort expectancy and facilitation conditions that enable the use of technology are good.

Limitations to the study was that it was an electronic survey, but there was also an option to recruit a person to assist when answering the questionnaire. It seems that most of the respondents were well educated and their incomes were high. As shown in previous studies, higher income or a higher degree may increase usage [3]. It is recommended that future studies should focus on lower income or lower education groups and those who are not able to answer electronic questionnaires.

\section{References}

[1] Hollmark M, Lefevre Skjöldebrand A, Andersson C, Lindblad R. Technology Ready to be Launched, but is there a Payer? Challenges for implementing eHealth in Sweden. Studies in Health Technology and Informatics. 2015;211:57-68.

[2] Craven J. Access to electronic resources by visually impaired people. In Information Research. 2003 Jul; 8(4):156.

[3] Reiners F, Sturm J, Bouw LJW, Wouters EJM. Sociodemographic Factors Influencing the Use of eHealth in People with Chronic Diseases. International Journal of Environmental Research and Public Health. 2019;16(4), 645.

[4] Liu L, Stroulia E, Nikolaidis I, Miguel-Cruz A, Rincon AR. Smart homes and home health monitoring technologies for older adults: A systematic review. International Journal of Medical Informatics. 2016 Apr; 91:44-59.

[5] Cresci M, Yarandi H, Morrel R. The Digital Divide and Urban Older Adults. Computers, Informatics, Nursing. 2010;28(2):88-94.

[6] Wildenbos GA, Jaspers MWM, Schijven MP, Dusseljee-Peute LW. Mobile Health for Older Adult Patients: Using an Aging Barriers Framework to Classify Usability Problems. International Journal of Medical Informatics. 2019;124:68-77.

[7] Trewin S, Pain H. Keyboard and mouse errors due to motor disabilities. International Journal of HumanComputer Studies. 1999b;50(2):109-144.

[8] Charness N, Boot WR. Aging and Information Technology Use: Potential and Barriers. In Current Directions in Psychological Science. 2009;18(5):253-258.

[9] Czaja S, Charness N, Fisk A, Hertzog C, Nair S, Rogers W, et al. Factors predicting the use of technology: Findings from the center for research and education on aging and technology enhancement (create). Psychology and Aging. 2006:21(2):333-352.

[10] Calvin KL, Karsh BT. The Patient Technology Acceptance Model (PTAM) for Homecare Patients with Chronic Illness. Proceedings of the Human Factors and Ergonomics Society Annual Meeting. October 2006 Oct; 50(10):989-993.

[11] Official Statistics of Finland (OSF): Population structure [e-publication]. ISSN=1797-5379. Helsinki: Statistics Finland. Referred: 2.12.2019. Access method: http://www.stat.fi/til/vaerak/index.html

[12] Venkatesh V, Morris MG, Davis GB, Davis FD. User Acceptance of Information Technology: Toward A Unified View. MIS Quarterly 2003;27(3):425-478.

[13] National Supervisory Authority for Welfare and Health (Valvira). Health care Equipment and Supplies. Referred: 25.1.2020 Access method: https://www.valvira.fi/terveydenhuolto/terveysteknologia/tuotteen_markkinoille_saattaminen/terveyden huollon_laitteet_ja_tarvikkeet

[14] Finnish Institute for Health and Welfare (THL). Classification of Diseases. ICD-10. Referred: 14.5.2020. Access method: https:/www.julkari.fi/bitstream/handle/10024/80324/15c30d65-2b96-41d7aca81a05aa8a019.pdf? sequence $=1$ \&isAllowed $=\mathrm{y}$, 